\title{
Vestígios de uma cultura escolar: os espaços escolares da Escola de Engenharia Industrial (1954-1960)
}

Traces of a school culture: the school spaces of Escola de Engenharia Industrial (1954-1960)

Rastros de una cultura escolar: los espacios escolares de la Escola de Engenharia Industrial (1954-1960)

\author{
VANESSA BARROZO TEIXEIRA ${ }^{1}$ \\ Elomar ANTONIO CALlEGARO TAMBARA ${ }^{2}$
}

\section{Resumo:}

Este trabalho investiga aspectos da cultura escolar da primeira instituição de ensino superior da cidade do Rio Grande, a Escola de Engenharia Industrial (EEI), levando em consideração a materialidade dos seus espaços escolares, tendo como período delimitador 1954 a 1960 . O espaço escolar, o "artefato fixo" (FUNARI, 2005) da EEI durante seis anos foi a Biblioteca Rio Grandense, bem como outros diferentes estabelecimentos de caráter educativo, industrial e esportivo. Para analisar essas transformações e mudanças em seus espaços escolares, a fotografia será utilizada como fonte documental, além dos relatórios e atas produzidos pela instituição, a fim de compreender a trajetória dessa instituição escolar até a transferência para seu edifício permanente.

Palavras-chave: Cultura escolar, Espaços escolares, Escola de Engenharia Industrial.

\footnotetext{
${ }^{1}$ Doutoranda e Mestre pelo Programa de Pós-Graduação em Educação da Universidade Federal de Pelotas, na Linha de pesquisa: Filosofia e História da Educação. Membro do Centro de Estudos e Investigações em História da Educação da Universidade Federal de Pelotas. Professora do Curso de Museologia da Universidade Federal do Rio Grande do Sul. E-mail: vteixeira2010@gmail.com

${ }^{2}$ Doutor em Educação pela Universidade Federal do Rio Grande do Sul. Professor do Programa de PósGraduação em Educação da Universidade Federal de Pelotas, na Linha de pesquisa: Filosofia e História da Educação. Coordenador do Centro de Estudos e Investigações em História da Educação. E-mail: tambara@ufpel.edu.br.
} 


\begin{abstract}
:
This work investigates aspects of school culture from the first higher education institution in the city of Rio Grande, the Escola de Engenharia Industrial (EEI), taking into consideration the materiality of their school spaces, with the delimiter period from 1954 to 1960. The school space, the "fixed artifact" (FUNARI, 2005) of EEI for six years was the Biblioteca Rio Grandense, as well as other different establishments of charather educational, industrial and sporting. To analyze these changes and the changes in their school spaces, the photograph will be used as a documental source, besides the reports and minutes produced by the institution in order to understand the trajectory of this educational institution until the transfer for their permanent building.
\end{abstract}

Keywords: School culture; School spaces;

\title{
Español:
}

Este trabajo investiga los aspectos de la cultura de la escuela de la primera institución de educación superior en la ciudad de Rio Grande, la Escola de Engenharia Industrial (EEI), teniendo en cuenta la importancia relativa de sus espacios escolares, con el período de 1954 a 1960 delimitador. El espacio de la escuela, el "artefacto fijo" (FUNARI, 2005) de la EEI durante seis años fue la Biblioteca Rio Grandense, así como otros establecimientos diferentes de carácter educativo, industrial y deportivo. Para analizar estos cambios y los cambios en sus espacios escolares, la imagen se puede utilizar como una fuente documental, además de los informes y actas producidas por la institución con el fin de comprender la trayectoria de esta institución educativa para transferir a su edificio permanente.

Palabras-clave: Cultura Escolar, Espacios Escolares, Escola de Engenharia Industrial. 


\section{Introdução}

O presente artigo aborda a questão dos espaços escolares da primeira instituição de ensino superior da cidade do Rio Grande, a Escola de Engenharia Industrial (EEI), criada em meados da década de 1950. Este estudo faz parte de um recorte de pesquisa de dissertação ${ }^{3}$ que tem como objeto de análise a história desta instituição escolar, a partir da sua cultura escolar que se encontra preservada em sua materialidade em alguns espaços de memória do município $^{4}$. Este trabalho abarcará o período de 1954 a 1960, época em que a EEI esteve alocada em espaços escolares provisórios. É significativo elucidar que a EEI inicia sua trajetória escolar em 1954 sem possuir um espaço físico, fator fundamental para qualquer instituição de ensino. Vale frisar que os espaços escolares de uma escola também fazem parte da sua constituição como tal, bem como da identidade e da memória individual e coletiva dos indivíduos que vivenciam aqueles espaços, inclusive fazendo parte da própria história da cidade a qual pertence.

Para que a EEI pudesse ser autorizada a funcionar pelo Ministério da Educação e Cultura (MEC), era necessário que a escola possuísse prédios adequados para ministrar as aulas para os futuros discentes. Portanto, sua entidade mantenedora a Fundação Cidade do Rio Grande, criada em 1953, percebe que seria imprescindível estabelecer vínculos institucionais com outros estabelecimentos localizados na cidade. Para isso foram firmados convênios com indústrias, fábricas, escolas e um clube esportivo, além de um contrato de comodato entre a Fundação e a Biblioteca Riograndense, estabelecimento escolhido para ser a sede provisória da EEI até sua transferência para seu prédio próprio. Através das fotografias presentes no Relatório de Inspeção de 1954, foi possível conhecer e analisar alguns dos espaços onde a EEI funcionou até 1960.

A fim de poder compreender como se estabelecem esses trâmites e quais eram esses espaços escolares provisórios da EEI procurou-se dividir o trabalho da seguinte forma. Primeiramente, será abordada a questão da relevância em se pesquisar a história das instituições escolares para a História da Educação, levando em consideração sua cultura escolar, nesse caso em específico, seus espaços escolares. Em seguida será analisada a trajetória da escola através dos seus espaços escolares provisórios, o que culminará na parte final do trabalho que tratará da transferência da EEI para seu edifício próprio em dezembro de 1960, juntamente com a formatura da primeira turma de alunos.

\footnotetext{
${ }^{3}$ Pesquisa de dissertação sob orientação do Prof. Dr. Elomar Antonio Callegaro Tambara, na linha de pesquisa de Filosofia e História da Educação no PPGE-FAE-UFPel.

${ }^{4}$ Dentre os espaços pesquisados é importante ressaltar o Núcleo de Memória Eng. ${ }^{\text { Francisco Martins Bastos }}$ (NUME), o Arquivo Geral da FURG e o acervo documental da Fundação Cidade do Rio Grande.
} 


\section{A história das instituições escolares como objeto de análise em História da Educação: caminhos para a reconstrução de uma cultura escolar}

A escolha dessa categoria de análise surge dentro da História da Educação como uma possibilidade de pesquisa, afinal trata-se de uma história institucional que corresponde à memória de um local, de um contexto e de indivíduos. Este novo foco da historiografia, característico dos novos paradigmas trazidos pela História Cultural, mudando a perspectiva do geral ao particular tem a intenção de demonstrar as diferenças e as semelhanças existentes nas singularidades de cada objeto de análise, privilegiando as instituições como "um arsenal de fontes e de informações fundamentais para a formulação de interpretações sobre elas próprias e, sobretudo, sobre a história da educação brasileira" (GATTI JÚNIOR, 2002: 4).

É o próprio conceito de fonte que se alarga. Em se tratando de história da educação, memórias, histórias de vida, livros e cadernos dos alunos, discursos em solenidades, atas, jornais de época, almanaques, livros de ouro, relatórios, fotografias, etc. são fontes importantíssimas. Assim, alguns dos nossos historiadores da educação passaram a pesquisar o particular, o pontual, o efêmero, renunciando à possibilidade de uma compreensão objetiva da realidade (BUFFA, 2000:19).

Trata-se justamente de uma análise investigativa que busca compreender a cultura organizacional da escola por meio dos elementos que constituem sua cultura escolar (NÓVOA, 1995). Esse novo olhar do campo educacional almeja,

[...] escapar ao vaivém tradicional entre uma percepção micro e um olhar macro, privilegiando um nível meso de compreensão e de intervenção. As instituições escolares adquirem umas dimensão própria, enquanto espaço organizacional onde também se tomam importantes decisões educativas, curriculares e pedagógicas [...] As escolas constituem uma territorialidade espacial e cultural, onde se exprime o jogo dos actores educativos internos e externos; por isso, a sua análise só tem verdadeiro sentido se conseguir mobilizar todas as dimensões pessoais, simbólicas e políticas da vida escolar, não reduzindo o pensamento e a acção educativa a perspectivas técnicas, de gestão ou de eficácia stricto sensu (NÓVOA, 1995: 15-16, grifos do autor). 
Além de procurar analisar as especificidades da instituição, essa categoria também visa reconstruir a instituição em sua totalidade, em sua organização como espaço escolar, um espaço capaz de alterar realidades, lugares e indivíduos. Afinal, conforme afirma Justino Magalhães

[...] a instituição educativa apresenta uma cultura pedagógica que compreende um ideário e práticas de diversa natureza, dados os fins, os actores, os conteúdos, inserida num contexto histórico e desenvolvendo uma relação educacional adequada aos públicos, aos fins, aos condicionalismos e às circunstâncias. A instituição educativa constrói um projecto pedagógico, indo ao encontro de um determinado público, constituindo-se, deste modo, a relação e a razão fundamentais para a manutenção e desenvolvimento de seu projecto educativo - um processo que envolve dimensões humanas, culturais e profissionais de diversas naturezas: dimensões pedagógicas, sociológicas, administrativas, relações de poder e de comunicação, relações de transmissão e apropriação do saber (MAGALHÃES, 1999:68-69).

Sobre isto é importante ressaltar que a história das instituições escolares também reúne a história dos espaços escolares, lugares que resguardam e que evidenciam a base material da escola. Para Werle (2004:22) essa história “é também história dos prédios escolares”, prédios que repercutem a identidade e a memória dessas instituições, assim como do contexto em que estão inseridas.

A história da instituição escolar, no que se refere à base material, precisa levar em consideração seus usos, as preocupações com beleza, segurança, funcionalidade, ampliações, reformas, transferências de espaços e da localização dos prédios e sua inserção no panorama local. À cidade como um todo pertence a escola e, portanto, a preservação da memória de instituições escolares está afeta ao ambiente no qual a escola se insere, às ruas e demais prédios, à vizinhança, ao bairro e à cidade (WERLE, 2004:24).

É significativo definir o que é cultura escolar antes de abordar a categoria espaços escolares, a fim de esclarecer como esse conceito está inserido na história dos estabelecimentos de ensino. Como já mencionado, a história das instituições engloba o que se denomina como cultura escolar, que em alguns casos específicos de preservação, pode ser analisada em sua materialidade. A cultura escolar representa um universo específico e repleto 
de características próprias. Segundo Julia (2001:10), a cultura escolar é responsável por delimitar um "conjunto de normas que definem conhecimentos a ensinar e condutas a inculcar, e um conjunto de práticas que permitem a transmissão desses conhecimentos e a incorporação desses comportamentos”. E quando se trata da sua materialidade é preciso frisar algumas questões.

Ao recortar o universo da cultura material especificando um domínio próprio, isto é, o dos artefatos e contextos materiais relacionados à educação escolarizada, a expressão não apenas amplia o seu significado reinserindo as edificações, o mobiliário, os materiais didáticos, os recursos audiovisuais, e até mesmo as chamadas novas tecnologias do ensino, como também remete à intrínseca relação que os objetos guardam com a produção de sentidos e com a problemática da produção e reprodução social (SOUZA, 2007:170).

Ainda sobre cultura escolar, um objeto de análise tão caro para a História da Educação, principalmente por ser o responsável por estudar as particularidades do universo escolar, ressalta-se que são vários os temas e questionamentos que podem ser analisados sob esse viés, como, por exemplo: "a constituição do currículo, a formação das disciplinas escolares, o cotidiano institucional, o exercício diário de professores e professoras, alunos e alunas, a materialidade da escola [...]" (VIDAL, 2005:5). Desse modo, acredita-se que por meio dessa cultura material escolar é possível conhecer e assim, reconstruir uma história institucional. Seguindo essa premissa encontra-se o objeto em questão desse trabalho, que trata sobre os espaços escolares e sua relevância na história das instituições escolares.

Os espaços escolares fazem parte da cultura escolar de cada instituição. O espaço escolar, também podendo ser pensado como um "lugar de memória" (NORA, 1993), é repleto de significados para aqueles que vivenciam suas instalações e para o próprio contexto no qual ele esta inserido. Ele faz parte da identidade da instituição, da sua memória e da sua história. Portanto, não se pode pensar que a transformação ou a constituição de um local determinado em um espaço escolar é neutra. Os usos, os espaços, as salas de aula, a biblioteca, a sala da diretoria e etc., todos esses elementos fundamentais para a criação de uma escola, são pensados. 
[...] a instituição escolar ocupa um espaço que se torna, por isso, lugar. Um lugar específico, com características determinadas, aonde se vai, onde se permanece umas certas horas de certos dias, e de onde se vem. Ao mesmo tempo, essa ocupação do espaço e sua conversão em lugar escolar leva consigo sua vivência como território para aqueles que com ele se relacionam. Desse lugar é que surge, a partir de uma noção objetiva - a de espaço-lugar -, uma noção subjetiva, uma vivência individual ou grupal, a de espaço-território (VINÃO, 2005:17).

Para este autor a instituição escolar faz parte de um todo complexo, no qual se incluem esses espaços determinados e que na concepção de Vinão-Frago, é um "espaço-lugar organizado arquitetonicamente para a realização de uma educação em sua forma escolarizada" (FARIA FILHO;OLIVEIRA, 2011:105). Partindo desse pressuposto é que Funari e Zarankin (2005:138) defendem que "a escola é, antes de tudo, um lugar planejado no espaço, formado por uma estrutura arquitetônica, dentro da qual têm lugar práticas vinculadas ao processo de ensino do saber "legítimo"”.

Ao pensar em uma escola, a primeira imagem que vem à nossa cabeça, provavelmente, é a de um edifício. Podemos dizer, então, que a representação mental que temos de uma escola é seu correlato físico (edifício). Sem dúvida, é necessário tornar claro que essa ideia de um prédio construído especificamente para funcionar como escola é um feito relativamente recente (meados do século XIX) e coincide com o estabelecimento da educação fundamental, pública e gratuita (FUNARI; ZARANKIN, 2005: 139).

No caso da EEI, foram vários os espaços que foram adaptados e que concederam a ela seu uso como estabelecimento de ensino, até que esta pudesse ser transferida para seu prédio sede, construído especificamente para as demandas de uma escola de engenharia. Estas e outras questões pontuais serão analisadas no decorrer deste trabalho.

\section{As primeiras instalações da EEI: um espaço escolar provisório}

Após a criação da Fundação Cidade do Rio Grande, em 1953, fica determinado o Conselho Diretor da entidade, o qual seria responsável por organizar todos os entraves para a criação da Escola de Engenharia Industrial. O primeiro presidente eleito pelo conselho foi o Eng. ${ }^{\circ}$ Francisco Martins Bastos, diretor-superintendente da Ipiranga S/A Companhia 
Brasileira de Petróleos, que após sua posse indica para o cargo de diretor provisório da EEI, o Eng $^{\circ}$ Cícero Marques Vassão, que naquele momento atuava como engenheiro chefe do Departamento Nacional de Portos, Rios e Canais do $18^{\circ}$ distrito. Este passou então a ser o responsável por articular e resolver as demandas pendentes para a criação da escola. Primeiramente, para que a escola enfim começasse a funcionar era necessário que esta possuísse um espaço físico que cumprisse com as exigências necessárias que compete uma instituição de ensino superior. Deveria possuir instalações para as salas de aula, espaço para reuniões e para a direção, bem como para a secretaria e administração da escola. A fim de que a EEI começasse a funcionar em seguida e cumprindo as normas exigidas pelo Ministério da Educação e Cultura (MEC), foi realizado um contrato de comodato, ainda no ano de 1953, entre a Fundação Cidade do Rio Grande, na pessoa do Eng ${ }^{\circ}$ Cícero Marques Vassão, vicepresidente da Fundação e diretor provisório da EEI, e do secretário Carlos Vignoli, com a Biblioteca Riograndense, representada pelo $\mathrm{Eng}^{\mathrm{o}}$ Fernando Duprat da Silva, vice-presidente em exercício, do secretário e do tesoureiro da biblioteca. É possível perceber através das autoridades envolvidas, que todos pertenciam ao movimento em prol do ensino superior da cidade do Rio Grande. Afinal, o vice-presidente da Biblioteca naquele momento, também viria a fazer parte das bancas examinadoras dos primeiros concursos de habilitação da EEI, bem como do futuro corpo docente da escola.

O espaço escolar escolhido como sede provisória para a EEI que foi concedido em comodato dizia respeito ao andar superior do referido prédio, o qual contava com uma sala de conferências, uma sala para a diretoria e mais cinco salas, as quais foram utilizadas para sala de reuniões e as demais para salas de aulas, sendo que uma ficou restrita à disciplina de Desenho. O contrato tinha duração de três anos, podendo ser prorrogado por igual prazo se caso "na data do seu término, a outorgada ainda não estiver instalada em seu prédio próprio" (RELATÓRIO, 1954). O que vem a acontecer, já que a EEI só é transferida para seu edifício sede apenas em 1960.

Nas fotografias do Relatório de Inspeção de 1954 percebe-se que os espaços foram devidamente organizados a fim de demonstrar que ali já estava pronto para funcionar um espaço escolar, e mais do que isso, uma instituição de Engenharia. Nota-se que um espaço como o de uma biblioteca realmente precisa ser modificado para receber uma instituição escolar, independente do seu grau de ensino. São espaços e usos que são modificados, bem como toda a rotina do lugar. É de se supor que apenas a sala de conferências e os sanitários fossem atribuições da própria biblioteca e que os demais ambientes foram adaptados para os fins da escola que ali passaria a funcionar durante seis anos. Como o foco deste trabalho é analisar e reconstruir a história da Escola de Engenharia Industrial por meio de sua cultura 
escolar que mantém-se preservada, levar-se-á em conta a análise fotográfica das imagens que evidenciam os espaços escolares da instituição. Na figura 1 que mostra uma das salas de aula da futura EEI percebe-se nitidamente a organização do espaço como sala de aula propriamente dita. As classes escolares substituídas por cadeiras sem mesas, contendo um único braço para o apoio do material escolar do aluno, a sua disposição em filas, lado a lado, preenchendo os espaços de circulação. Logo a frente encontra-se a mesa designada ao professor, contendo uma cadeira e talvez o que seria um apagador ou caixa com giz para o quadro negro, que se situa próximo à mesa do professor. Um quadro relativamente pequeno em suas proporções e não fixado na parede, o que reforça a assertiva anterior de que este espaço foi adaptado para receber a estrutura de uma escola, neste caso, uma escola de Engenharia. Um detalhe significativo é pensar nas mudanças deste espaço público que foi adaptado para ser escolar, afinal trata-se de uma biblioteca pública municipal. Todos esses cuidados devem ter sido muito bem recomendados ao fotógrafo, afinal essas imagens foram selecionadas para fazerem parte de um documento de caráter oficial que foi avaliado pelo Ministério da Educação.

Figura 1 - Sala de aula localizada no prédio da Biblioteca Riograndense, década de 1950.

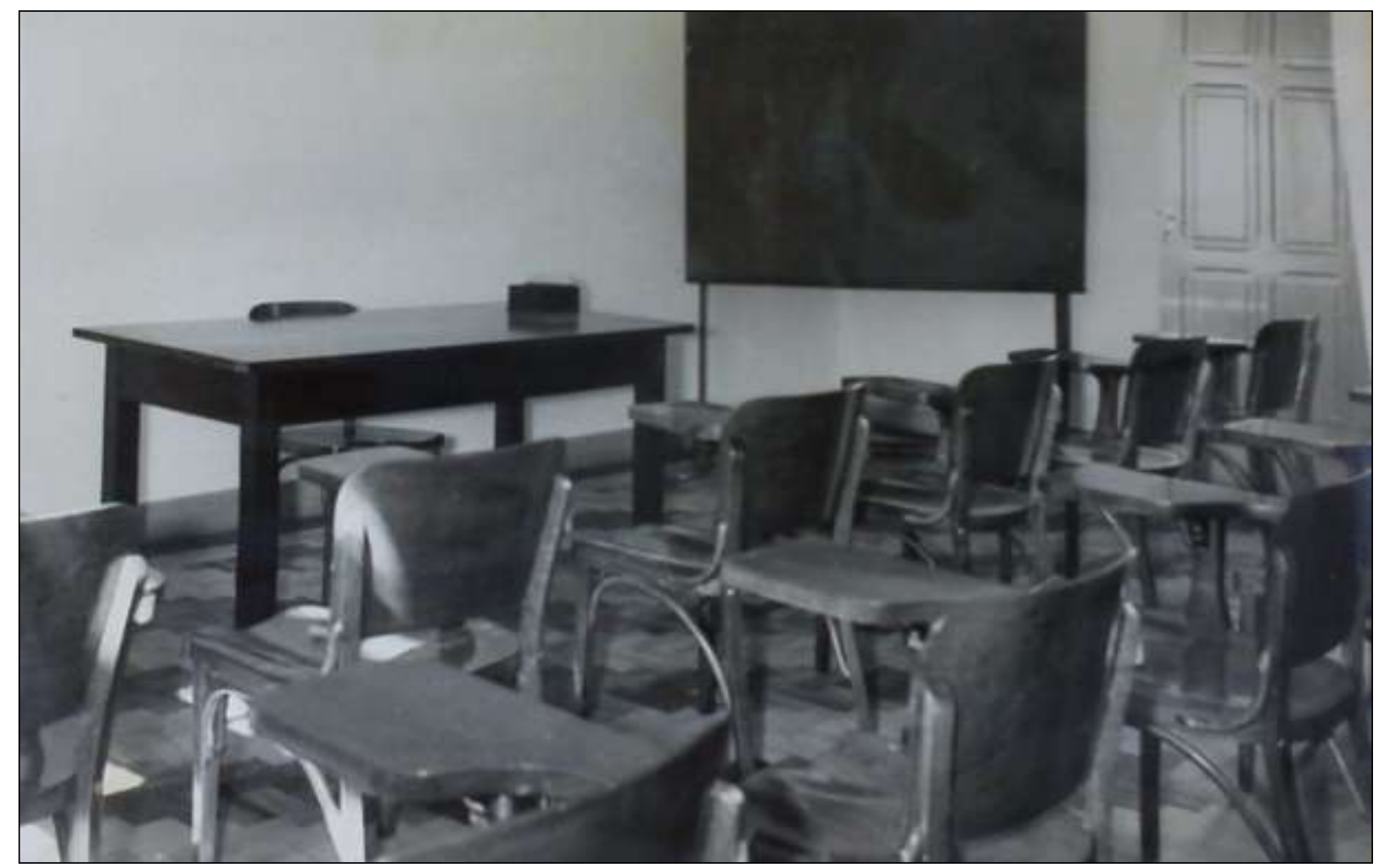

Fonte: Relatório de Inspeção da EEI, 1954. Acervo do NUME 
Sobre as instalações provisórias da escola, localizadas no segundo andar da Biblioteca Riograndense, maiores detalhes são explicitados pelo Conselho Diretor da Fundação Cidade do Rio Grande em relatório escrito no ano de criação da EEI, antes do efetivo início das atividades da mesma.

O prédio, no qual funcionará a Escola, preenche satisfatóriamente, as exigências para o fim a que se destina, sendo fartamente iluminado com luz natural e elétrica e amplamente arejado. No pavimento superior, estão localizadas as salas da Diretoria, da Secretaria e aulas, além de amplo salão para conferências e atos solenes. As instalações sanitárias, nos dois pavimentos, preenchem os requisitos higiênicos, reclamados para estas dependências. A escada é de fácil acésso, larga e bem iluminada. A Biblioteca Rio Grandense, situada no pavimento térreo, com mais de 100.000 volumes em obras gerais e cêrca de 15.000 técnicos, confére à Escola condições ideais quanto à consulta bibliográfica (RELATÓRIO, 1954:2).

Através desse contrato, a EEI já estava apta para ministrar suas aulas, dirigir a instituição, além de poder desenvolver outras atividades como, por exemplo, palestras, conferências e sediar eventos. Todavia, para um curso como o de Engenheiro Industrial modalidade Mecânica era preciso muito mais do que aulas teóricas e palestras para a formação deste profissional. E pensando na necessidade de aulas práticas, imprescindíveis para a constituição do profissional engenheiro, foram feitos alguns convênios com empresas e indústrias do município, a fim de auxiliar na constituição dos primeiros engenheiros formados na cidade do Rio Grande. Para tanto, a Fundação Cidade se mobilizou durante todo o ano de 1954 solicitando convênios e parcerias entre espaços que possuíssem laboratórios, oficinas e equipamentos industriais que pudessem ceder esses ambientes, entre outros, para a aprendizagem dos estudantes da EEI. É importante ressaltar que para que a escola fosse autorizada a funcionar, ela precisaria contar com todas as instalações necessárias para a formação de engenheiros industriais mecânicos, antes de realizar seu primeiro vestibular. Desse modo, a entidade mantenedora da escola começou a articular os convênios necessários para que a instituição pudesse funcionar. Para o ensino prático de física e química foram feitos dois convênios com dois colégios, um privado dirigido pelos Irmãos Maristas e outro estadual, o Colégio São Francisco e o Colégio Lemos Jr, respectivamente. Para ambos, o convênio deixava bem claro que sem qualquer ônus, seriam utilizados pelos alunos da escola os laboratórios, gabinetes de física e seus respectivos equipamentos, sempre levando em 
consideração o regimento interno de cada instituição. Além disso, as aulas práticas deveriam contar com no máximo cinco alunos, sempre acompanhados por um professor da EEI, afinal as aulas eram de total responsabilidade da escola. Para o controle do que estava sendo ministrado, além da duração e do número de aulas práticas, no início de cada ano letivo, a EEI deveria repassar para os colégios o programa prático das disciplinas que necessitariam do uso do laboratório, com o intuito de não prejudicar o funcionamento normal do mesmo.

As aulas práticas aplicadas pela EEI tanto nos colégios, como em outros estabelecimentos, deveriam ser avaliadas por meio de relatórios feitos pelos alunos. Nos convênios com os colégios São Francisco e Lemos Jr consta, assim como nos demais convênios, que "do melhor relatório apresentado pelos alunos, uma cópia poderá ser fornecida ao Colégio mediante pedido, a título de cooperação da Escola e reconhecimento pelas facilidades proporcionadas ao ensino" (RELATÓRIO, 1954).

Além dessas instituições escolares, a EEI também assinou um convênio com a Escola de Aprendizagem Industrial "João Simplício", criada e mantida pelo Serviço Nacional de Aprendizagem Industrial (SENAI) criada em 1942 pelo Governo. Era uma escola profissional de nível pós-primário e mista, portanto permitia que tanto homens quanto mulheres pudessem cursá-la. A Escola de Aprendizagem estava caracterizada como uma instituição de ensino técnico voltada para o ramo industrial, que possuía as condições necessárias para auxiliar a EEI em seus primeiros passos. Por possuir oficinas e salas de aulas específicas, foi realizado um convênio com esta escola afim de utilizar alguns de seus espaços, como, por exemplo, a sala de desenho e a sala de ensino e tecnologia mecânica. A figura 2 permite visualizar o investimento que vinha sendo feito no ensino técnico-profissional, afinal, trata-se de uma sala, que poder-se-ia denominar como sendo uma oficina, na qual encontram-se distribuídos, equipamentos, mesas, armários e uma série de aparelhos utilizados para o ensino de tecnologia mecânica. A existência de espaços consolidados e com infraestrutura como esta instituição, demonstram a base fértil que existia para a implantação de uma instituição de Engenharia Industrial na cidade, mesmo que está ainda não possuísse instalações próprias. Evidentemente, esses convênios possuíam um prazo de duração, com possibilidade de ser renovado, entretanto, caberia a Fundação Cidade do Rio Grande enquanto mantenedora da EEI pleitear a aquisição de um espaço escolar próprio para a escola almejando que esta um dia se tornasse uma instituição de referência no que tange o ensino de Engenharia. Outras disciplinas práticas necessitavam ser contempladas e para isso, os lugares para essas aulas se encontravam no próprio parque industrial da cidade do Rio Grande. 
Ao analisar os convênios que foram feitos em benefício dos primeiros anos da escola, não se pode acreditar plenamente que estes eram os espaços "ideais" de ensino para os estudantes, contudo, é preciso notar que naquele momento estas eram as únicas opções para que a escola pudesse ser autorizada a funcionar, caso contrário, o ensino superior de Rio Grande continuaria no plano das ideias.

Figura 2 - Sala de ensino de tecnologia mecânica da Escola de Aprendizagem Industrial "João Simplício", década de 1950.

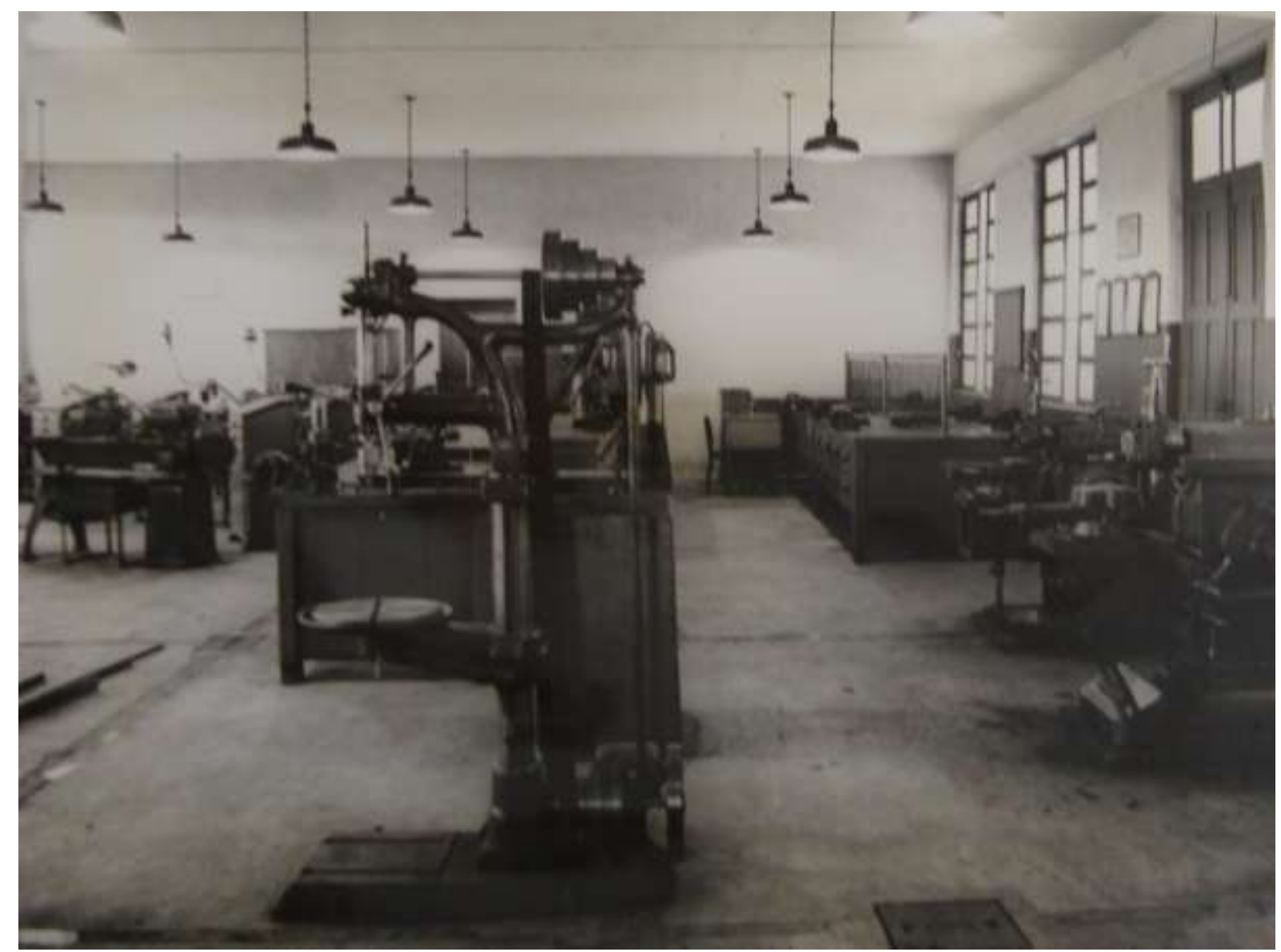

Fonte: Relatório de Inspeção da EEI, 1954. Acervo do NUME.

Mesmo enfrentando um período de "crise" durante a década de 1950 (MARTINS, 2006) resultado proveniente do cenário mundial pós-guerra, o setor industrial riograndino resistia e tinha como uma de suas principais empresas, a Ipiranga Cia Brasileira de Petróleos S/A. Empresa que, ao contrário das demais, lucrou com a Segunda Guerra Mundial. O Eng ${ }^{\circ}$ Francisco Martins Bastos, considerado um dos personagens principais da criação da EEI, além de desempenhar a função de diretor-superintendente da Ipiranga, era presidente da 
Fundação Cidade do Rio Grande desde 1953, professor catedrático e membro da Congregação de professores da escola. Portanto, era de se esperar que a empresa concedesse seus espaços para auxiliar na implementação das aulas práticas da instituição. Para isso, colocava à disposição da escola todo o aparelhamento industrial, assim como seus laboratórios. As demais especificações com relação ao número de alunos, presença de professores, programa prático das disciplinas, entre outras exigências, permaneciam as mesmas já tratadas nos outros convênios. Contudo, a refinaria solicitava em contrapartida que além da escola realizar qualquer tipo de reparo ou avaliação técnica sem custo à empresa, também deveria desenvolver pesquisas técnicas relacionadas ao ramo industrial. É importante lembrar que a maioria dos professores pertencentes ao corpo docente da escola eram funcionários da Ipiranga, portanto, essa solicitação viria a contribuir tanto para as disciplinas como para a própria melhoria nos setores da empresa. Além desse requerimento, a refinaria admitiria que os alunos da escola, além das aulas práticas pudessem realizar estágios durante o período de férias da escola. Sobre os convênios realizados pela Fundação, o diretor da EEI, Cícero Vassão em relatório que aborda as atividades desenvolvidas pela Diretoria durante o ano letivo de 1962 apresentado à Congregação de professores, enfatiza os primeiros anos da escola, suas dificuldades e a participação ímpar desta empresa e de seus funcionários.

Sentíamos que a vida universitária não podia se restringir a aulas, conhecimento de programas, realização de provas mensais e parciais. Era necessário que a Escola se dinamizasse, levando a todos os seus integrantes o exato sentido da responsabilidade que todos assumiam, fortificasse o espírito universitário, objetividade sem utilitarismo, enfim uma série interminável de necessidades. Felizmente as bases da Escola eram relativamente sólidas, pois nascera ela com a participação efetiva da indústria, particularmente a Refinaria de Petróleo Ipiranga, diretamente e através de seus eminentes técnicos, colaborando decidida e desinteressadamente com a nossa administração (RELATÓRIO, 1962:3).

Outras empresas também aceitaram conveniar-se à Fundação Cidade do Rio Grande com intuito de participar deste movimento que intentava criar a primeira instituição de ensino superior do município. Dentre esses estabelecimentos industriais encontram-se a Companhia União Fabril, antiga Fábrica Rheinghantz, e a Companhia Fiação e Tecelagem Rio Grande, as quais forneciam seus laboratórios, teares, maquinário mecânico e a vapor, incluindo caldeiras. Ambas foram indústrias têxteis de grande importância para a economia local desde o início do 
século XX. Juntamente com a Companhia União Fabril, a Companhia Fiação e Tecelagem Rio Grande tinha sua produção voltado ao mercado têxtil ligada a manufatura de algodão, matéria-prima esta que era importada do Nordeste do Brasil.

Fundada no final do século XIX, foi uma empresa implantada por imigrantes italianos, a qual empregava mais de 600 operários, em sua maioria mulheres (MARTINS, 2006). Como essa era uma empresa que se encontrava em pleno funcionamento na época, atuante na economia local, foi uma das opções possíveis de espaço para prática dos estudantes da EEI. Essa diversificação dos ramos e das possibilidades de atuação dos futuros engenheiros pode ter sido positiva na formação desses profissionais, que necessitavam conhecer cada tipologia de indústria e de matéria-prima para entender o funcionamento desses estabelecimentos.

O Departamento Nacional de Portos, Rios e Canais do $18^{\circ}$ Distrito também assinou convênio para auxiliar no andamento das aulas práticas da EEI. Pode-se pensar que a participação ativa do Eng. ${ }^{\circ}$ Cícero Vassão na trajetória da criação da Fundação Cidade e consequentemente, da Escola de Engenharia Industrial, sendo primeiro diretor, membro da Congregação e professor catedrático da instituição, foi fundamental para a efetivação deste convênio, já que nesta mesma época ele atuava neste departamento federal como engenheiro chefe, o que pode ter facilitado o processo. Além do departamento nacional, o Departamento Estadual de Portos, Rios e Canais também fornecia suas instalações para o uso da EEI. Ao todo ficavam à disposição da escola: laboratórios, oficinas mecânicas, instalações portuárias e inclusive, um dique seco em pleno funcionamento.

O Serviço Riograndino de Eletricidade e o de Transportes Coletivos também faziam parte do convênio. O serviço municipal de eletricidade fornecia suas caldeiras de alimentação automática, um elevador para carvão e sua sub-estação de transformadores, todos setores atuando concomitantemente ao empréstimo de seus espaços para as aulas práticas dos primeiros estudantes de engenharia da cidade do Rio Grande. Este fato demonstrava que os alunos teriam a oportunidade de presenciar e vivenciar a realidade de diversos setores industriais do município, podendo avaliar os pontos positivos e as presenças e ausências de tecnologia e mão de obra qualificada. O Serviço Riograndino de Transportes Coletivos permitia que a EEI tivesse acesso a sua oficina mecânica e à suas seções de torno e de soldagem. A figura 3 ilustra um desses espaços e através dela pode-se perceber que se trata de um lugar que realiza o conserto e a manutenção de peças mecânicas, peças provenientes dos meios de transporte da época. É importante notar que nesse período, década de 1950, o meio de transporte coletivo eram os bondes elétricos. Um outro detalhe nessa imagem é a presença 
de dois, supostos funcionários desse serviço público, um mais velho localizado ao fundo recostado sobre uma peça, e um outro bem mais próximo ao fotógrafo, de boina escura e com uma expressão de concentração sob o que estava a fazer. Nenhum dos dois encara a máquina fotográfica, ambos desviam o olhar. Pode-se perceber que este com a boina escura é um jovem rapaz que talvez ainda não tenha concluído o ensino secundário e que se encontra no mercado de trabalho. Fato que não era incomum neste período, onde mulheres, crianças e jovens eram mãos de obra barata e útil para a maioria das indústrias da cidade do Rio Grande (PAULITSCH, 2008). Por meio dessa imagem, fica evidente a precariedade dos espaços que os alunos da EEI teriam suas aulas práticas, diferentemente de um espaço criado especificamente para ser uma oficina ou um laboratório criado pela instituição escolar. Outro dado perceptível é a desqualificação da mão de obra que atuava nesses espaços, jovens sem formação na área, além da falta de segurança no trabalho, fato que talvez fosse comum na época, mas que seria melhor analisado se fizesse parte de uma prática de ensino dentro da escola.

Figura 3 - Visão parcial da oficina mecânica do Serviço Riograndino de Transportes Coletivos, década de 1950.

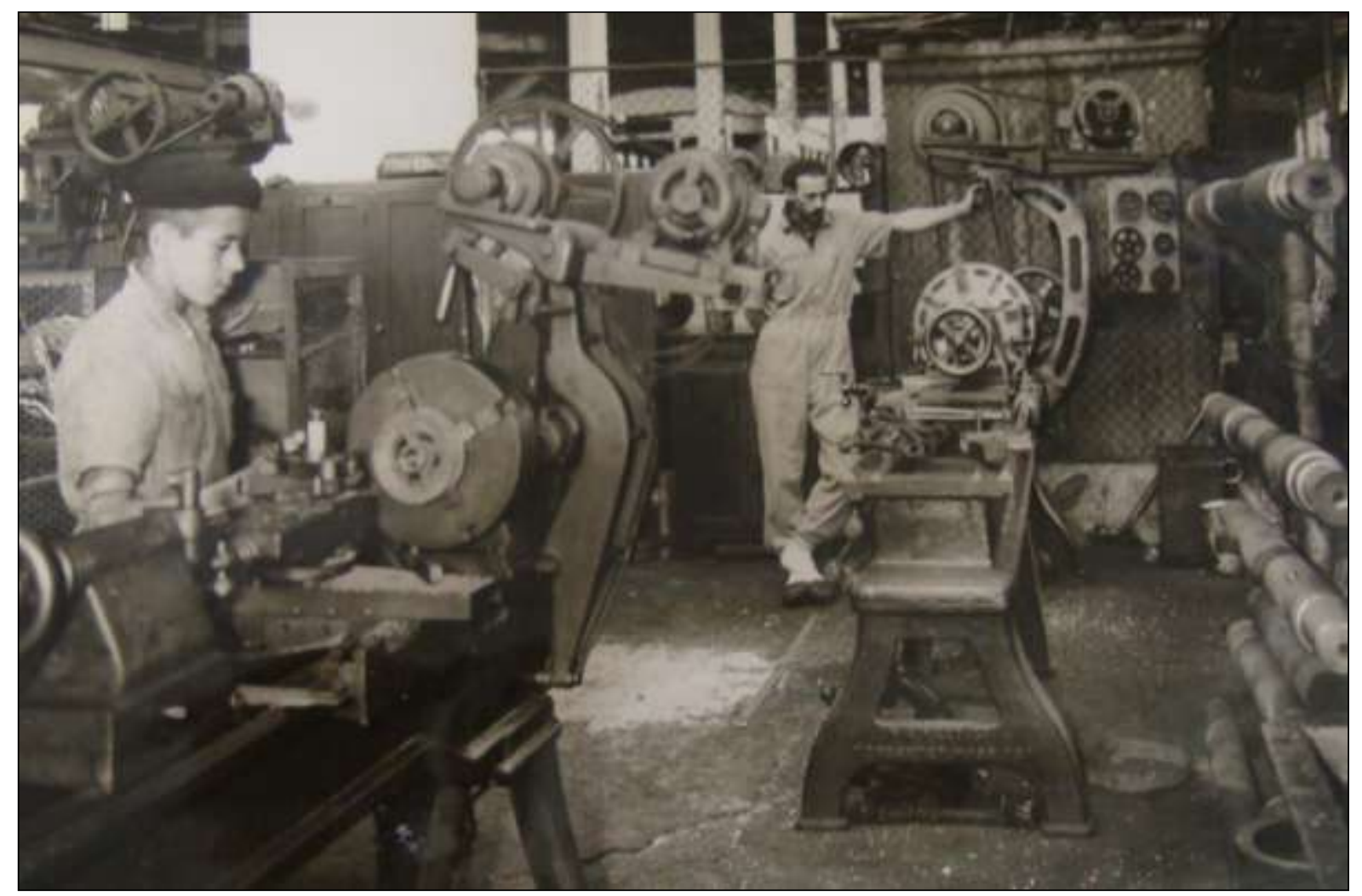

Fonte: Relatório de Inspeção da EEI, 1954. Acervo do NUME. 
Uma instituição que chama a atenção nesta lista de espaços conveniados à Fundação Cidade do Rio Grande é a de um espaço para aulas de Educação Física. Trata-se do Club de Regatas Rio Grande (CRRG), que firmou convênio para que os alunos da escola pudessem desempenhar suas atividades físicas e esportivas em suas instalações. Tais instalações compreendiam "canchas de "basket-ball”, "voley-ball”, "tenis", pistas para corridas, barcos para a prática de remos, álteres, discos, etc. etc.” (RELATÓRIO, 1954:s/n). Mesmo não estando explicitada na listagem de disciplinas escolares da escola, a prática de Educação Física, bem como a participação em eventos esportivos fazia parte da rotina dos estudantes da EEI e de muitas instituições de Engenharia do país (HASSEN;FERREIRA,1996). Este seria um possível exemplo do que Forquin (1995) ilustra como sendo o "currículo oculto" de algumas instituições escolares, ou seja, disciplinas escolares ou programas escolares que não constam no "currículo oficial" da escola, mas que fazem parte da sua realidade escolar.

No referido convênio fica estabelecido que as práticas esportivas ou exercícios físicos deveriam sempre acontecer com a presença de um professor de Educação Física, contratado pela escola. Não é possível afirmar que esta fosse uma disciplina de caráter obrigatório na EEI, contudo, existem fotografias no acervo fotográfico do NUME que mostram os alunos da EEI com uniformes da escola participando de campeonatos de basquete, futebol de salão e de campo, o que confirma que a prática desportiva era incentivada pela escola.

Durante os anos de 1954 a 1960 a Escola de Engenharia Industrial funcionou nesses espaços provisórios e conveniados, espaços que auxiliaram a consolidar a imagem e a própria identidade dessa instituição através dos seus espaços escolares. No final da década de 1960 a EEI é enfim transferida para seu prédio próprio, um prédio projetado para receber a infraestrutura necessária para uma instituição de ensino superior voltada para o ensino de engenharia.

\section{O espaço escolar próprio: a inauguração do edifício sede da EEI}

O edifício sede construído para abrigar toda a estrutura da Escola de Engenharia Industrial é inaugurado no mesmo dia da primeira formatura da escola, no dia 28 de dezembro de 1960. Localizado na rua Coronel Sampaio, sem numeração na época, mais tarde esta rua viria a receber um outro nome, passando a denominar-se Eng. ${ }^{\circ}$ Alfredo Huch (BORTHEIRY, 2008). Uma homenagem a um dos primeiros professores da instituição, que também exerceu a função de diretor da escola entre os anos de 1963 e 1964 (MAGALHÃES, 1997: 65). 
Um prédio de grandes proporções foi construído, em um terreno bem próximo ao da Refinaria de Petróleo Ipiranga, antiga Ipiranga S/A Companhia Brasileira de Petróleos, cuja denominação foi alterada em 1959 (CESAR, 2011). É válido recordar que parte deste terreno havia sido doado em meados da década de 1950 pelo Sr. Adelino Campos Assumpção, e o restante do mesmo foi comprado pela Fundação Cidade do Rio Grande em 1957. Dividido em três zonas, algumas ainda em fase de construção ou ainda para serem iniciadas, possuía dois pavimentos onde funcionariam os órgãos administrativos, didáticos e de pesquisas, além de um grande auditório, que ainda se encontrava na planta, com capacidade para 300 pessoas (RELATÓRIO, 1960: 2). Dentro dessa parte já construída encontra-se as salas para aulas teóricas, salas de desenho, gabinetes de física e química, bem como as salas para os professores, incluindo a sala para a Congregação e para o Conselho Técnico Administrativo. No final da década de 1960, este edifício (Figura 4) já possuía seis laboratórios específicos para aplicação das disciplinas práticas, como Tecnologia Mecânica e Metalurgia, além de 16 salas de aula com capacidade para 35 alunos (COLMEIA DO PROGRESSO, s/d:5).

Figura 4 - Vista aérea do prédio sede da Escola de Engenharia Industrial. Década de 1960.

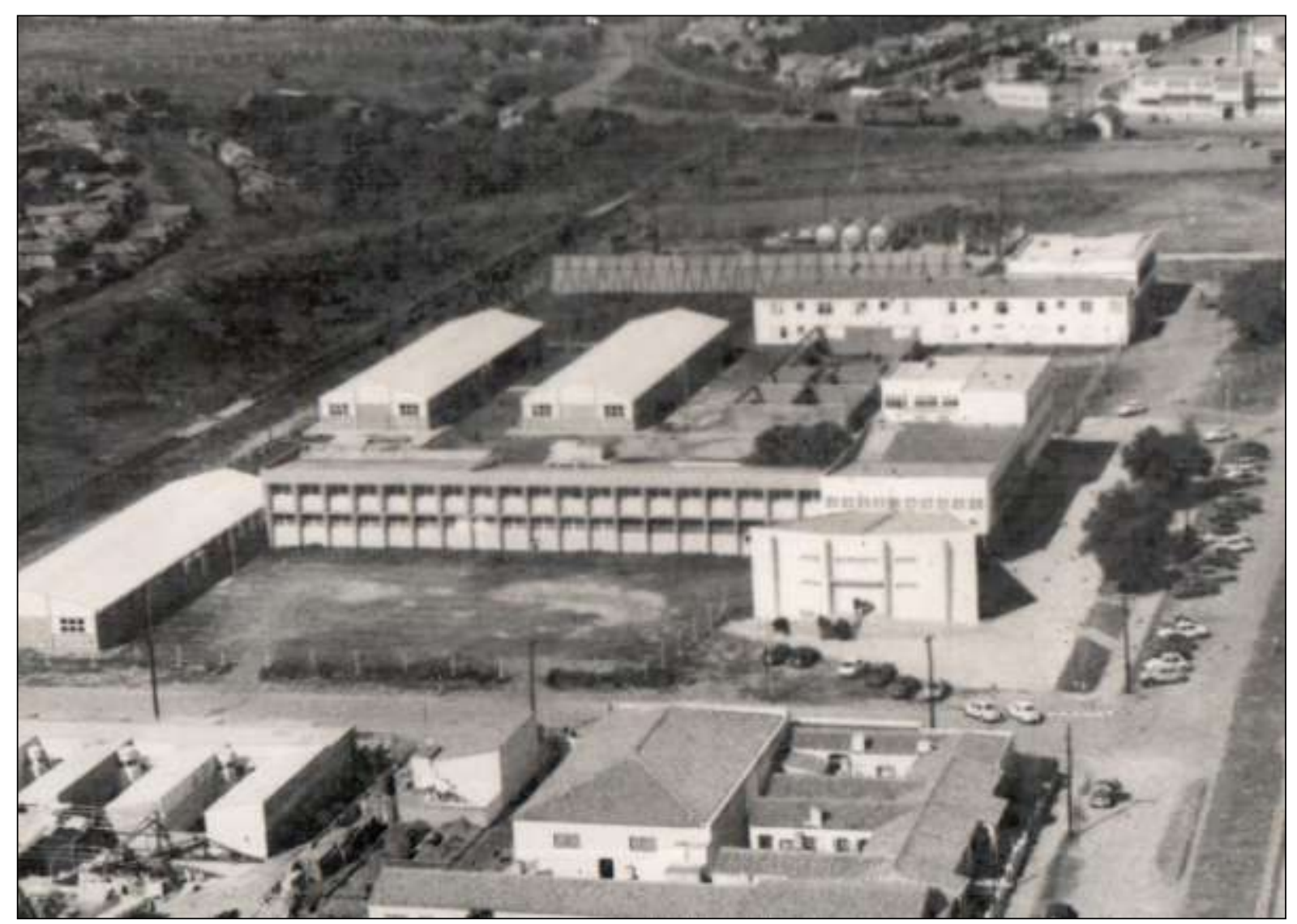

Fonte: Acervo do NUME. 
As perspectivas sobre o novo espaço escolar, bem como sua relevância para um ensino qualificado de engenharia, são retratadas em relatório redigido pelo diretor da EEI, Eng. ${ }^{\text {o }}$ Cícero Vassão.

[...] a Escola se constituiria em um centro de desenvolvimento, estudando e analisando os problemas que impediriam o progresso industrial dos municípios, situados em sua área de influência. Considerar ainda a participação da Escola no instante de transição que passa o Brasil na era tecnológica que vem a ingressar, de modo a preocupar-se futuramente com o desenvolvimento de pesquisas técnicas e científicas que viessem a contribuir para superar e ultrapassar com segurança o citado estado de transição (RELATÓRIO, 1962:2).

A inauguração do espaço escolar próprio da EEI contou com a presença da comunidade riograndina, de autoridades políticas e eclesiásticas, bem como de algumas personalidades ilustres que podem ser consideradas por aqueles envolvidos na criação da escola, como de auxílio fundamental durante a trajetória da instituição até este momento solene. O Reitor da Universidade do Rio Grande do Sul (URGS), Dr. Eliseu Paglioli foi um dos ilustres convidados presentes.

Esse novo espaço buscava englobar todas as necessidades que um estabelecimento de ensino superior voltado para a engenharia industrial necessitava abarcar. Por tais razões além da construção do edifício sede, foi construído um pavilhão com oficinas e outro para Eletrotécnica. Em relatório escrito pelo diretor Cícero Vassão, ele aborda a necessidade de ampliação do pavilhão de oficinas, pois este já não comporta o crescente desenvolvimento da escola, precisando de mais máquinas e aparelhos (RELATÓRIO, 1962: 17). Outros espaços encontravam-se em construção, como já mencionado, dentre eles estava o auditório, um pavilhão para o almoxarifado e escritórios, um para Metalurgia e Operações Unitárias, incluindo Termodinâmica, além de vestiários e sanitários para as instalações de caráter industrial. Uma infraestrutura que visava um espaço adequado e moderno, capaz de reunir todas as especificidades que uma escola de engenharia necessita. 


\section{Considerações finais}

Partindo dos pressupostos de uma análise histórico institucional pretendeu-se valorizar a constituição dos espaços escolares como elementos de uma cultura escolar que auxiliaram na construção da identidade e da memória de uma instituição de ensino. Após elencar e analisar algumas possíveis questões e hipóteses sobre a relevância dos espaços escolares pode-se compreender como estes espaços são cruciais para a trajetória das instituições escolares, principalmente pelo fato de serem alicerces de memórias individuais e coletivas que vivenciam aquelas estruturas físicas. Sem esquecer que esses prédios além de contarem a história das instituições que resguardam, também contam a própria história da cidade da qual fazem parte.

Analisando os espaços escolares provisórios que a Escola de Engenharia Industrial perpassou é necessário considerar alguns fatores. Mesmo com todas as vantagens citadas pelos convênios que eram feitos com as instituições que concediam seus espaços para a escola, é perceptível, que dentre tantas indústrias na cidade, apenas três de caráter privado, um órgão federal, um estadual e dois municipais foram "selecionados" por suas instalações para fazerem parte dos convênios com a Fundação Cidade. Isto demonstra que estes talvez não fossem os melhores e mais adequados espaços para as práticas de alunos de Engenharia, mas sim os que se disponibilizaram a acatar o movimento. Portanto, fica claro que tratava-se de um grupo de empresários e de profissionais da cidade que tinham certo interesse em participar desse empreendimento voltado para o ensino superior, tanto pela contrapartida oferecida pelo convênio, como pela oportunidade de conseguir novos profissionais específicos para atuarem em seus espaços.

É significativo notar que a criação desse estabelecimento de ensino não estava sendo pensado apenas para Rio Grande, mas sim, visava abranger todo o interior do estado do Rio Grande do Sul, que carecia de espaços de ensino superior, principalmente no que tange o ensino de engenharia, já que a única instituição existente no estado estava localizada em Porto Alegre. O que se percebe no discurso dos relatórios e dos demais documentos analisados, incluindo atas, regimentos e fotografias, é que a escola estava sendo construída para suprir uma demanda de mão de obra qualificada da indústria local. Entretanto, a partir desse levantamento que consta no relatório de criação da instituição fica implícito que este não era o único objetivo da escola, mas sim, tornar-se uma referência em formação de engenheiros e fornecer esses profissionais para o interior do estado do Rio Grande do Sul, em específico a 
metade sul. Afinal, é de se supor que a metade norte já estivesse sendo contemplada com os engenheiros formados pela Escola de Engenharia localizada na capital. A iniciativa pioneira desse grupo e dessas empresas visava organizar e proporcionar uma escola que formasse não apenas engenheiros, mas cidadãos capazes de lidar e transformar problemas da cidade e da região, em soluções.

Vale ressaltar que este trabalho de pesquisa que trata da história da primeira instituição de ensino superior da cidade do Rio Grande/RS é apenas uma leitura sobre essa história institucional, dentre tantas outras possíveis de serem realizadas. Ao mesmo tempo em que não se pretende esgotar o tema abordado, nem mesmo as fontes pesquisadas. Almeja-se que mais pesquisas e consequentemente, mais histórias sobre a Escola de Engenharia Industrial possam ser contadas.

\section{Referências}

BORTHEIRY, Aída Luz Meirelles. Memória FURG - NUME: fragmentos da história da Fundação Universidade Federal do Rio Grande segundo os Arquivos do Núcleo de Memória Engenheiro Francisco Martins Bastos. Rio Grande: Fundação Universidade do Rio Grande, 2008.

CESAR, Willy. Chico Bastos, o pescador. Rio de Janeiro: UniverCidade, 2011.

COLMEIA DO PROGRESSO. Rio Grande. Fundação Cidade do Rio Grande, s/d.

FARIA FILHO, Luciano Mendes; OLIVEIRA, Marcus Aurélio Taborda de. Antonio Vinão Frago: a crítica da educação como crítica cultural. In: Memória, história e escolarização. Petrópolis, RJ: Vozes; São Paulo, SP: Revista Educação; Editora Segmento, 2011, p. 93-124. FORQUIN, Jean-Claude. Escola e Cultura: as bases sociais e epistemológicas do conhecimento escolar. Porto Alegre: Artes Médicas, 1995.

FUNARI, Pedro Paulo; ZARANKIN, Andrés. Cultura material escolar: o papel da arquitetura. In: Revista Pro-Posições. Dossiê Cultura escolar e cultura material escolar: entre arquivos e museus. Faculdade de Educação, UNICAMP: Campinas, SP. Vol. 16, nº1 (46), jan/abr, p.135-144, 2005.

GATTI JÚNIOR, Décio. A história das instituições educacionais: inovações paradigmáticas e temáticas. In: Novos temas em história da educação brasileira: instituições escolares e educação na imprensa. Campinas, SP: Autores Associados; Uberlândia, MG, 2002, p. 3-24.

HASSEN, Maria de Nazareth; FERREIRA, Maria Letícia Mazzucchi. Escola de Engenharia/UFGRS - Um século. Porto Alegre: Tomo editorial, 1996. 
JULIA, Dominique. A Cultura Escolar como objeto histórico. In: Revista Brasileira de História da Educação. Campinas: Autores Associados. No 1. jan/jun de 2001.

MAGALHÃES, Justino Pereira de. Breve apontamento para a história das instituições educativas. In: História da Educação: perspectivas para um intercâmbio internacional. Campinas, SP: Autores Associados, Histedbr, p. 67-72, 1999.

MAGALHÃES, Mario Osório. Engenharia, Rio Grande: História \& algumas histórias. Pelotas: Ed. Armazém Literário, 1997.

MARTINS, Solismar Fraga. Cidade do Rio Grande: industrialização e urbanidade (18731990). Rio Grande: Editora da FURG, 2006.

NORA, Pierre. Entre memória e história: a problemática dos lugares. In: Projeto História. PUC, São Paulo, no 10, p. 7-28, dez/ 1993.

NOSELLA, Paolo; BUFFA, Ester. Universidade de São Paulo; Escola de Engenharia de São Carlos; os primeiros tempos: 1948-1971. São Carlos: EdUFSCar, 2000.

NÓVOA, António. Para uma análise das instituições escolares. In: As organizações escolares em análise. Lisboa: Publicações Dom Quixote, Instituto de Inovação educacional, p. 13-43, 1995.

PAULITSCH, Vivian da Silva. Rheingantz: uma vila operária em Rio Grande. Rio Grande: Editora da FURG, 2008.

RELATÓRIO apresentado à Congregação da Escola de Engenharia Industrial da cidade do Rio Grande. Prof. Eng ${ }^{\circ}$ Cícero Marques Vassão (Diretor da EEI). Rio Grande, 1962.

RELATÓRIO de Inspeção da Escola de Engenharia Industrial da cidade do Rio Grande. Fundação Cidade do Rio Grande, 1954.

RELATÓRIO do $2^{\circ}$ período letivo da Escola de Engenharia Industrial da Fundação Cidade do Rio Grande. Dr. Ruy Poester Peixoto (Inspetor Federal). Rio Grande, janeiro de 1960.

SOUZA, Rosa Fátima de. História da cultura material escolar: um balanço inicial. In: Culturas escolares, saberes e práticas educativas: itinerários históricos. São Paulo: Cortez, 2007, p.: 163-189.

VIDAL, Diana Gonçalves. Cultura e prática escolares: uma reflexão sobre documento e arquivos escolares. In: A cultura escolar em debate: questões conceituais, metodológicas e desafios para a pesquisa. Campinas, SP: Autores Associados, p. 3-30, 2005.

VIÑAO-FRAGO, Antonio. Espaços, usos e funções: a localização e disposição física da direção escolar na escola graduada. In: História da Educação, arquitetura e espaço cultural. São Paulo: Cortez, p. 15-47, 2005.

WERLE, Flávia Obino Corrêa. História das instituições escolares: de que se fala? In: LOMBARDI, José Claudinei e NASCIMENTO, Maria Isabel Moura. (Org.). Fontes, História e Historiografia da Educação. Campinas: Autores Associados, p 13-33, 2004. 